Liu, L., Ripley, D., \& Lee, A. (2016). Flipped Learning and Influential Factors: Case Analysis. Journal of Educational Technology Development and Exchange, 9(2), 85-103.

\title{
Flipped Learning and Influential Factors: Case Analysis
}

\author{
Leping Liu \\ University of Nevada, Reno \\ Darren Ripley \\ University of Nevada, Reno \\ Angela Lee \\ University of Nevada, Reno
}

\begin{abstract}
Flipped learning has been a focus of research to explore potential learning environments that may positively affect student learning. The key issue is whether or how educators design such a learning environment, and what might be the factors that educators need to consider when designing a flipped learning environment. The first part of this study presents a critical review and analysis on factors identified from the literature that may influence the success of a flipped-learning case. 216 cases selected from current literature were analyzed on seven factors (Overall Design, Design of Information, Design of Technology Use, Active Learning, Motivation, Special Guidance, and Self-Regulated Learning) regarding their influence on the success of flipped learning experiences. Among them the first five factors were found to be significant and included in a prediction model. The second part of this study demonstrates an ongoing case of flipped learning that reflects and examines the prediction model.
\end{abstract}

Keywords: flipped learning, influential factors, Instructional Design

\section{Introduction}

Educators have been exploring potential learning environments that impact student learning in a positive way, and flipped learning or classroom flipping is such an environment gradually gaining prominence among educators and policy makers (Lee \& Liu,
2016; Sams \& Bergmann, 2013). According to a report from the Speak Up National Research Project, in a period of two years from 2012 to 2014, more than 2600 schools in the United States moved to a flipped learning environment (Project Tomorrow, 2015). Paralleled with educators' practice, more and more studies in flipped learning are completed 
and added to the literature (Herreid \& Schiller, 2013; Persky \& Dupuis, 2014). Figure 1 also shows the trends of research interests in this theme from 2011 to resent.

Very often, in an approach to explore effectiveness of a new method or application in education, non-significance is a common phenomenon in early research (Liu, Maddux \& Johnson, 2008), and the same as in flipped learning research. With experimental or quasiexperimental designs, researchers examine the differences in learning outcomes between students from a traditional classroom and a flipped learning environment, but usually have no-significant-difference results, for example, in collegiate technology courses (Davies, Dean, \& Ball, 2013), college chemistry courses (Baepler, Walker, \& Driessen, 2014), and undergraduate engineering courses (Velegol, Zappe, \& Mahoney, 2015). According to such research findings, can it be concluded that the no-difference results indicate no impact or a negative impact of flipped learning on student learning? The answer is no, as flipped learning would improve student learning if it is implemented following careful procedures of an efficient instructional design model (Goodwin \& Miller, 2013; Ng, 2014). Therefore, more explorations may focus on the design of a flipped learning environment that would positively affect student learning, and factors that may influence the success of flipped learning experiences (Fulton, 2014; Persky \& Dupuis, 2014).

The purposes of current study are (a) to critically review, examine, and identify factors that may influence students flipped learning from current literature, and formulate a literature based prediction model, and (b) to examine the model through an on-going flipped learning cases: a flipped Calculus class.

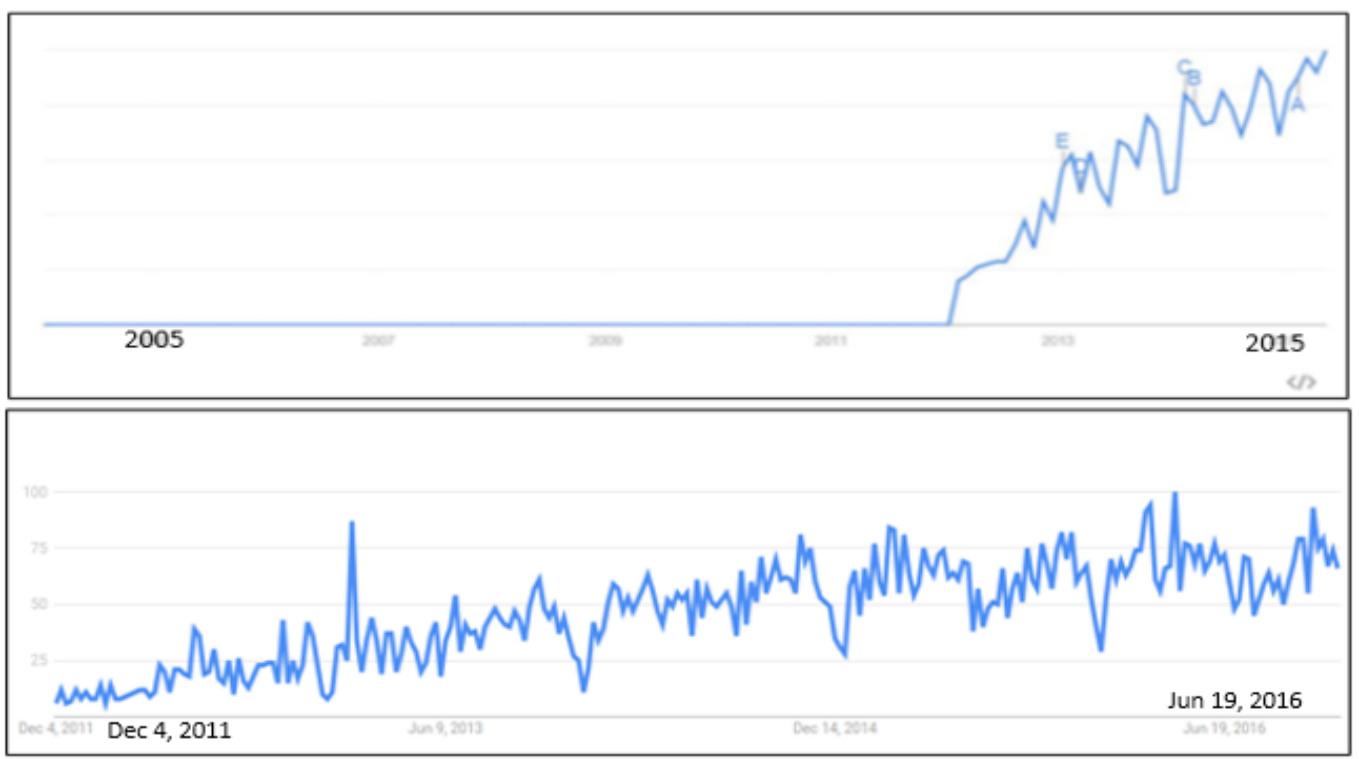

Figure 1. Trends of flipped learning (Google Trends, 2016) 


\section{Literature Review}

\subsection{What is Flipped Learning?}

The flipped learning model, commonly known as classroom flipping, is first clearly defined by Ramsey Mussalam as "Classroom Flipping is the practice of taking direct instruction and moving it from the group learning environment to the individual learning environment (2012). More specific, the main idea is to shift the attainment of learning content before class in the form of instructional videos, recorded lectures, and other remotely accessible instructional materials. Then, the in-class time is spent to apply the material through higher level problem solving, deeper conceptual comprehension, and peer collaboration( Hamdan, McKnight, McKnight, \& Arfstrom,2013; Strayer, 2012).Hamdan and colleagues (2013) also introduce a set of best practices for educators and administrators wishing to flip all or part of their curriculum. They use the predictable acronym, "FLIP", to briefly highlight guidelines for the practice of flipping:

(F) Flexible Learning Environments. It is an environment by virtue of the fact that learners can choose when and where to acquire content, and teachers should foster this ethos in learners to alter the classroom environment to supplement content acquisition (Hamdan, et al., 2013).

(L) Shift in Learning Culture. Teaching under the flipped paradigm will shift from the "sage on the stage" to the "guide on the side" (King, 1993). Teachers will need to relinquish some control of their classes and assume more collaborative roles with students (Chen, Wang, Kinshuk, \& Chen, 2014).

(I) Intentional Content. Educators are expected to critically evaluate which content is appropriate for flipping and which must be delivered by direct instruction (Huba \& Freed, 2000). Then, intentionally designed contents are used to engage students' active learning (Liu \& Maddux, 2008a).

(P) Flipping Requires Professional Educators. Flipping requires hard-working, skilled, well-educated teachers who are sensitive to the needs of their students and dedicated to the field of education to create learning environments where students reach their full potential (Gojak, 2012).

The common definitions and key features summarized above provide a framework to explore factors influencing the effectiveness or success of a flipped learning experience.

\subsection{What May Influence Flipped Learning?}

As in any initial attempt of instructional practice, theoretical guidance is necessary when creating or evaluating such a flexible learning environment that shifts the learning culture from teacher-centered to teacherstudent-collaborative and delivers intentionally designed learning contents. One applicable instructional design theory in the field is the ADDIE model, which lines out the main principles in the five stages of instructional design: Analysis, Design, Development, Implementation, and Evaluation (Branson, Rayner, Cox, Furman, \& King, 1975; Gagne, Wager, Golas, \& Keller, 2005). Furthermore, in the design of technology-based instructions, the ADDIE model can be merged into an ITD technology integration model, where Information (contents), Technology (tools), and Design (strategies and methods) formulate a 3-D system that applies ADDIE components to produce effective instructions (Liu \& Henderson, 2003; Liu \& Maddux, 2008a). Based on these two models, the following seven factors are revealed from the literature:

Overall Design. This is the decision 
making on overall strategies or methods of flipped learning. After analyzing the needs of learners, features of the content subject, objectives of the instruction, and the available resources (including faculty and technology equipment), instructors and school principals will decide if a "full flip" or "partial flip" would best benefit student learning. (Leung, Kumta, Jin, \& Yung, 2014; McLaughlin, Gharkholonarehe, \& Esserman, 2014). This decision will lead to the outcomes of (a) how flexible the learning environment could be, and (b) to what extent the teacher-studentcollaborative learning activities could be performed.

Design of Information. Subject content is the main part of instruction. How will content be taught or learned? It is not that simple to just "flip" the instructional materials for a traditional classroom to a flipped classroom. Design of "intentional contents" generally is completed with tasks and procedures in the analysis and design stages of the ADDIE model (Liu \& Henderson, 2003; Liu \& Johnson, 2002). For example, objectiveoriented materials, learning-style-driven activities, or student-need-based guidance all need careful attention. Especially, instructions or activities before, during, and after the classroom time (Enfield, 2013) require a dynamic design (Liu, \& Maddux, 2005, 2010) that allows students to go through all the procedures of learning in an effective way.

Design of Technology Use. Another dimension to implement flipped learning is the appropriate use of technology tools. As described in the ITD model (Liu \& Henderson, 2003), one consideration is the selection of technology for certain types of content information to be delivered (e.g., texts, sounds, pictures, movies, 3-D simulated illustrations), or certain types of activities to be performed (e.g., group work, synchronized or a synchronized communications). Typical decisions can be whether to choose a public or institutional online platform, or to use an existing or instructor-created video (Engin, 2014; Chen, Wang, Kinshuk, \& Chen, 2014). Recently, creating materials that are I-phone or I-pad accessible is another effort instructors have made (Chai, Wong, \& King, 2016).

Active Learning. In the literature of flipped learning, active learning is a key concept often mentioned (Holmes, Tracy, Painter, Oestreich, \& Park, 2015; Roach, 2014; Roehl, Reddy, \& Shannon, 2013). It features instructional methods that actively engage learning, such as collaborative learning and problem-based learning (Prince, 2004). It addresses the flexible learning environment and the flipped learning culture, where Special Guidance to students with special needs, another factor influence flipped learning, can be provided (Michael, 2006).

Motivation. Motivation has been found a predictor variable that influences computerbased learning (Liu \& Jones, 2004; Liu \& Maddux, 2008b; Chai, et al., 2016), and flipped learning consistently (Herreid \& Schiller, 2013). It is one of the main themes generated from a content analysis of over 200 current articles on flipped learning (See Figure 2).

Self-Regulated Learning. Zimmerman and Schunk (2001) promoted a Selfregulated learning model that consists of four interrelated learning processes: self-evaluation and monitoring, goal setting and strategic planning, strategy implementation and monitoring, and, strategy outcome monitoring. The model introduces a set of systematical practice and is suggested to be effective to improve learning performances, (Chen, 2009; Lee \& Liu, 2016). Most current studies in flipped learning are still exploring the ways to adopt this model. 


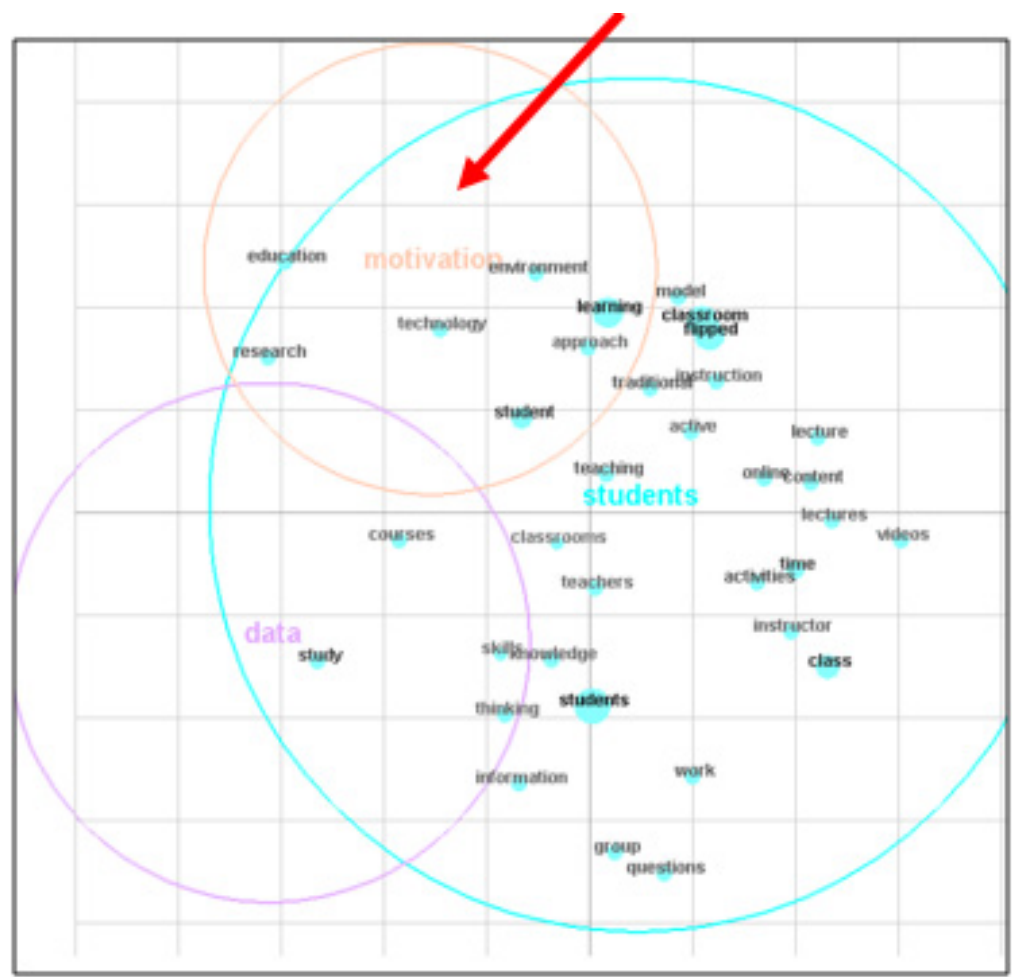

Figure 2. Themes in flipped learning literature

In summary, from the literature, the seven factors (Overall Design, Design of Information, Design of Technology Use, Active Learning, Motivation, Special Guidance, and Self-Regulated Learning) are of the authors' interest. A critical content analysis in flipped learning literature is introduced next, and the seven factors are examined whether or to what extent they could influence the possibility of a flipped learning case to be successful as described in the literature.

\section{Case Analysis: Influential Factors}

\subsection{Research Question}

The case analysis was guided by the following research questions:

1. Can the probability that a flipped learning case is successful be predicted by any of the seven variables -overall design, design of information, design of technology use, active learning, motivation, special guidance, and selfregulated learning?

2. To what extent do the significant variables (if any from question 1) influence the probability of a flipped learning case to be successful?

\subsection{The Sample of Flipped Learning Cases}

The sample of cases were selected from flipped learning literature over the past five years. More than 250 referred journal articles were reviewed including quantitative studies, qualitative studies, and on-going projects. Cases were identified from the articles according to the experiences described by the authors. A case from an article was selected 
and coded so long as the article provides necessary information for the analysis: the learners, the learning subject, procedures of the flipped learning experiences, and outcomes from the learners and their experiences. It does not critical whether the case is from a quantitative study, qualitative study, or ongoing project.

In totally 216 flipped learning cases were selected for the case analysis. Course levels ranged from K-12 (32.9\%) to college and graduate $(67.1 \%)$ courses. The subject content areas varied from mathematics (19.9\%), languages $(8.3 \%)$, social sciences $(7.9 \%)$, literacy $(10.6 \%)$, psychology $(6.9 \%)$, science (13.0\%), engineering $(5.6 \%)$, health $(6.0 \%)$, medicine $(6.5 \%)$, economics $(3.2 \%)$, business (7.9\%), education $(2.8 \%)$, and music $(1.4 \%)$.

\subsection{Factors Examined and Coding}

Again, the purpose of the case analysis is to explore the factors or variables that influence the probability of a flipped learning cases to be successful as described in the literature. In this analysis, the response variable is Case Success (CS), where success is defined by student learning outcomes from their flipped learning experiences as described in the articles. For a given case selected from an article, a value of 1 is coded for "success" when any one of the criteria is met: (a) flipped learning results in better learning outcomes if the outcomes are quantitatively measureable such as evaluation scores, (b) flipped learning exhibits expected features in student learning performance if the outcomes are summarized from observations or qualitative data, or (c) flipped learning shows positive trends in learning performance towards improved learning outcomes if the case is an on-going study. Otherwise, a value of zero is coded for an "unsuccessful" case. The seven factors summarized from the literature are explanatory variables (or predictor variables). They are coded as in the following.

For the three design related factors, Overall Design (OD),Design of Information (DI), and Design of Technology Use (DT), they are coded as 1 for a given case, if instructional design principles, tasks and procedures are employed and details are specifically explained in the article from which the case was selected. Otherwise, a value of zero is given to code the variables as "design not presented" for the case.

The other four factors, although still under the scope of design in the ITD model, are specified as method related factors: Active Learning (AL), Motivation (MO), Special Guidance (SG), and Self-Regulated Learning (SR). They are coded as 1 for a given case, if the article provides detailed descriptions of the strategies, methods, activities, or models used to establish an active learning environment, to motivate student learning, to provide special guidance to those with special needs, and to apply any of the self-regulated learning processes in the flipped learning case. A value of zero is given for the absence of the features in a variable. Table 1 shows the coding values for the variables.

\subsection{Data Analysis and Results}

Logistic regression analyses were conducted to determine whether Overall Design (OD), Design of Information (DI),Design of Technology Use (DT), Active Learning (AL), Motivation (MO), Special Guidance (SG), and Self-Regulated Learning (SR)could be used to predict the success of a flipped learning case (Case Success). The assumptions of logistic regression were checked and no violations were found. Frequencies for each variable are shown in Table 2. 
Table 1. Variable Coding

\begin{tabular}{lll}
\hline \multirow{2}{*}{$\begin{array}{l}\text { Variables } \\
\text { presented in articles) }\end{array}$} & Values \\
\cline { 2 - 3 } & 1 & 0 \\
\hline$(\mathrm{CS})-$ Case Success (RV) & Successful & Unsuccessful \\
\hline$(\mathrm{OD})-$ Overall Design (EV) & Yes & No \\
\hline$(\mathrm{DI})-$ Design of Information (EV) & Yes & No \\
\hline$(\mathrm{DT})-$ Design of Technology Use (EV) & Yes & No \\
\hline$(\mathrm{AL})-$ Active Learning (EV) & Yes & No \\
\hline$(\mathrm{MO})-$ Motivation (EV) & Yes & No \\
\hline$(\mathrm{SG})-$ Special Guidance (EV) & Yes & No \\
\hline$(\mathrm{SR})-$ Self-Regulated Learning (EV) & Yes & No \\
\hline
\end{tabular}

Note: $R V$-Response Variable, EV_Explanatory Variable

Table 2. Frequencies

\begin{tabular}{lll}
\hline \multirow{2}{*}{ Variables } & \multicolumn{2}{l}{ Values } \\
\cline { 2 - 3 } & 1 & 0 \\
\hline$(\mathrm{CS})-$ Case Success & 149 & 67 \\
\hline$(\mathrm{OD})$ - Overall Design & 155 & 61 \\
\hline$(\mathrm{DI})$ - Design of Information & 101 & 115 \\
\hline$(\mathrm{DT})$ - Design of Technology Use & 128 & 88 \\
\hline$(\mathrm{AL})-$ Active Learning & 128 & 88 \\
\hline$(\mathrm{MO})-$ Motivation & 142 & 74 \\
\hline$(\mathrm{SG})-$ Special Guidance & 117 & 99 \\
\hline$(\mathrm{SR})-$ Self-Regulated Learning & 116 & 100 \\
\hline
\end{tabular}


First, a logistic regression analysis was performed with all seven explanatory variables. The results showed that the model was significant $\left(\mathrm{X}^{2}=44.485, p<0.001\right)$, but two of the seven variables did not significantly contribute to the model: Special Guidance (Wald $\mathrm{X}^{2}=0.434, p=0.510$ ) and SelfRegulated Learning (Wald $\mathrm{X}^{2}=0.741, p=$ $0.389)$. Therefore, these two variables were eliminated from the model in the next model examination. The five explanatory variables included in the next logistic regression analysis were: Overall Design (OD), Design of Information (DI), Design of Technology Use (DT), Active Learning (AL), and Motivation (MO).

Results from the second logistic regression showed that the second model with these five explanatory variables was significant $\left(\mathrm{X}^{2}=\right.$ 44.443, $p<0.001$ ) and accounted for about $26 \%$ of the variation in the response variable $\left(\mathrm{R}^{2}=\right.$ 0.257), indicating that this model significantly predicts group membership. The Hosmer and Lemeshow Goodness-of-Fit Statistic of 3.523 $(p=0.833)$ was not significant, indicating that the hypothesis that the model provides a good fit of data should be accepted. Specifically, 26 out of 67 unsuccessful cares (38.8\%), 140 out of 149 successful cases $(93.9 \%)$, and a total of 166 out of 216 cases $(76.8 \%)$ were correctly predicted by the model.

A significant Wald chi-square value for a given variable indicates that the variable is significantly related to the response variable. As shown in Table 3, the Wald chi-square values are significant for all five explanatory variables. Therefore, all five explanatory variables are included in the model equation. The Parameter Estimate generates the estimated coefficients of the fitted logistic regression model, and they are used to formulate the following logistic regression equation (1):

$$
\begin{aligned}
& \operatorname{logit}\left({ }^{\wedge} p\right)=-1.628+0.898(O D)+ \\
& 0.869(D I)+0.915(D T)+0.744(A L)+ \\
& 0.773(M O)+--(1)
\end{aligned}
$$

The sign $\left({ }^{\wedge} p\right)$ indicates an estimated probability value (also called log odds) for the response variable (Case Success) to be 1 , and

Table 3. Logistic Regression Outputs

\begin{tabular}{lllllll}
\hline & DF & $\begin{array}{c}\text { Parameter } \\
\text { Estimate }\end{array}$ & $\begin{array}{c}\text { Standard } \\
\text { Error }\end{array}$ & $\begin{array}{c}\text { Wald } \\
\text { Chi-Square }\end{array}$ & $\boldsymbol{P}$ & $\begin{array}{c}\text { Odds } \\
\text { Ratio }\end{array}$ \\
\hline$(\mathrm{OD})$ & $\mathbf{1}$ & 0.898 & 0.351 & 6.556 & $0.010^{*}$ & 2.456 \\
\hline$(\mathrm{DI})$ & $\mathbf{1}$ & 0.869 & 0.343 & 6.408 & $0.011^{*}$ & 2.385 \\
\hline$(\mathrm{DT})$ & $\mathbf{1}$ & 0.915 & 0.330 & 7.695 & $0.006^{*}$ & 2.497 \\
\hline$(\mathrm{AL})$ & $\mathbf{1}$ & 0.744 & 0.337 & 4.884 & $0.027^{*}$ & 2.104 \\
\hline$(\mathrm{MO})$ & $\mathbf{1}$ & 0.773 & 0.345 & 5.001 & $0.025^{*}$ & 2.166 \\
\hline Constant & 1 & -1.628 & 0.442 & 13.566 & $0.001^{*}$ & 0.196 \\
\hline
\end{tabular}

Response variable: Case Success (CS), [*]: significant at an alpha level of .05

Explanatory variables: Overall Design (OD), Design of Information (DI), Design of Technology Use (DT), Active Learning (AL), and Motivation (MO) 
logit represents logit transformation of the event probability.

An estimated coefficient indicates the contribution that particular explanatory variable makes to the possibility of the response variable being 1 . For example, when the variable $A L$ (Active Learning) is 1 (that is, when active learning strategies or activities are applied in the flipped learning experience), the logit transformation of event probability (that the flipped learning case to be successful as described in the literature) increases by 0.744 (see Table 3 ). The estimated coefficients for the other four explanatory variables can be interpreted the same.

Odds ratio is another statistic to explain the contribution of an explanatory variable to the model. If the odds ratio for a given explanatory variable is larger than 1 , the probability of the response variable being 1 increases because of the presence of that explanatory variable. For example, the odds ratio for variable $A L$ (Active Learning) is 2.104 (see Table 3), indicating that a flipped learning case would be 2.104 times more likely to be successful if active learning is engaged in the case, compared to cases that do not engage active learning. If the odds ratio is smaller than 1 , the probability of the response variable being 1 decreases (that is, the probability of a flipped learning case to be successful decreases when that explanatory variable exists). As seen in Table 3, all five odds ratio values are larger than 1 , therefore, all five variables positively contribute to the success of a flipped learning case.

\subsection{Summary of the Case Analysis}

In summary, five influential factors are identified: overall design, design of information, design of technology use, active learning, and motivation. Data analysis results suggest that the probability of a flipped learning case to be successful increases when (a) overall design is carefully done in analyzing the needs and determining the level of flipping, (b) course contents are intentionally designed to meet the requirements of a flipped learning environment and the diversified needs of students, (c) technology tools are chosen appropriately to deliver content materials or perform learning activities, (d) active learning strategies are integrated into the content design or activity design, and (e) all the designs take into consideration how to motivate student learning.

It seems that these are some common knowledge. However, very often people "do" it but not carefully consider the depth of "design." For example, in most of the cases, videos or recorded lectures are used, and some issues are always followed but not considered thoroughly. Existed videos are used but they may not fit into the curriculum or the objectives of a particular lesson. Instructor created videos vary in quality as it requires the instructor's knowledge of instructional design (and of course technology skills, and available equipment). A recorded lecture, when delivered to students, can be an audio file or a video file. It is actually a piece of media from which students learn. How well students learn from the flipped contents before class to certain extent does depend on the quality of such media. This is the reason that such emphasis is put on design.

Addressing back to the purpose and research questions of the case analysis, a prediction model with the five explanatory variables are summarized next.

\subsection{Model Function}

Results and relationships produced from the logistic regression data analysis can be summarized into the following model function equation (2) in Figure 3. 
Model function (2) reads "the probability of a flipped learning case to be successful is a function of overall design, design of information, design of technology use, active learning, and motivation." It exhibits the relations between the group of explanatory mathematics and instructional technology. He has more than five years' experiences in designing and teaching flipped classes, and has created more than 300 instructional videos on the topics of Calculus, PreCalculus, Business Calculus, and Statistics (Ripley, 2016).

$\mathrm{P}(\mathrm{CS})=f[$ OD, DI, DT, AL, MO]

Where:

$$
\begin{aligned}
& \mathbf{C S}=\text { Case Success } \mathbf{P}(\mathbf{C S})=\text { Probability of Case Success } \\
& \mathbf{O D}=\text { Overall Design } \quad \mathbf{D I}=\text { Design of Information } \\
& f[\ldots] \text { indicates "a function of ..." } \\
& \mathbf{A L}=\text { Active Learning } \quad \mathbf{M O}=\text { Motivation } \\
& \text { DT }=\text { Design of Technology Use }
\end{aligned}
$$

Figure 3. Model function

variables and the response variable. Logistic regression equation (1) in the "Data Analysis and Results" section is the concrete model that describes all specific predictive relations or influences. This model basically is a literature based model, and it is being examined in an on-going flipped learning case.

\section{A Flipped Calculus Class: To Examine the Model}

This section presents a real flipped learning case. The case basically addresses the factors reviewed in previous section. The purposes to visit this case are (a) to explore best practice in flipped learning, and (b) to examine the prediction model generated from the cases in literature.

\subsection{Participants}

This is an on-going flipped learning case with a Calculus class from an academy in a western state of the United States. The class consists of 25 gifted-talented students aging from 11 to 17 . They are taught according to their intelligence development level with special curriculum that reaches the maximum limit of their learning. The instructor of this flipped class has duo-background in

\subsection{A Sample Class for Flipping: Settings and Procedures}

Knowing the special needs and the capabilities of his students, the instructor saw the potential that flipped learning could help them to achieve higher level performance of learning. He decided to "flip" the Calculus class. The procedures of the flipped Calculus class are described next.

Instructor Created Video Lectures. All videos are produced by the instructor using a screen capture software package Camtasia (TechSmith.com), a Wacom Bamboo Tablet, and a set of Logitech microphone/camera. The length of videos varies from 15 minutes to 40 minutes. An example reviewed by the authors of this article is one that contains all content relevant to the material in Chapter 2.1 from Stewart's Calculus: Early Transcendentals (7th Edition, 2015), including lectures on theory and sample problem solving. The purpose of the video is to provide students with the theoretical and graphical background for understanding derivatives.

In producing all video lectures for the Calculus course, the instructor followed the procedures of analysis, design and 
development in ADDIE model as creating an instructional video. The videos are clearly structured, objective-oriented, with strict logics and very informative contents intentionally designed for flipped learning (Ripley, 2016). Figure 4 shows some sample videos by the instructor over time.

Course Delivery System. A widely used online learning management system Blackboard (WebCT) is used for the flipped class. All information including class schedules, Notes pages for "flipped" requirements, assignments for pre-practice, and video lectures for intentional contents of the topics are available to students at all times on Blackboard (WebCT). Students who miss class have unlimited access to all information by virtue of their access to Blackboard.

Student Requirements before Class. Video lectures and necessary materials required for students to review before class are posted on the Blackboard course section. Student requirements before class are:

1. Students will go to Blackboard and download a copy of the "Notes" page with sample problems from the homework section for the lesson, which they can use as formative assessments. The "Notes" page is a blank page with the sample problems on the bottom. Clearly, students can simply use a sheet of blank paper and write down the problems they will need to do after completing the video. There are never more than two or three problems and they are rudimentary in difficulty level.

2. Students will go to Blackboard and view the videos.

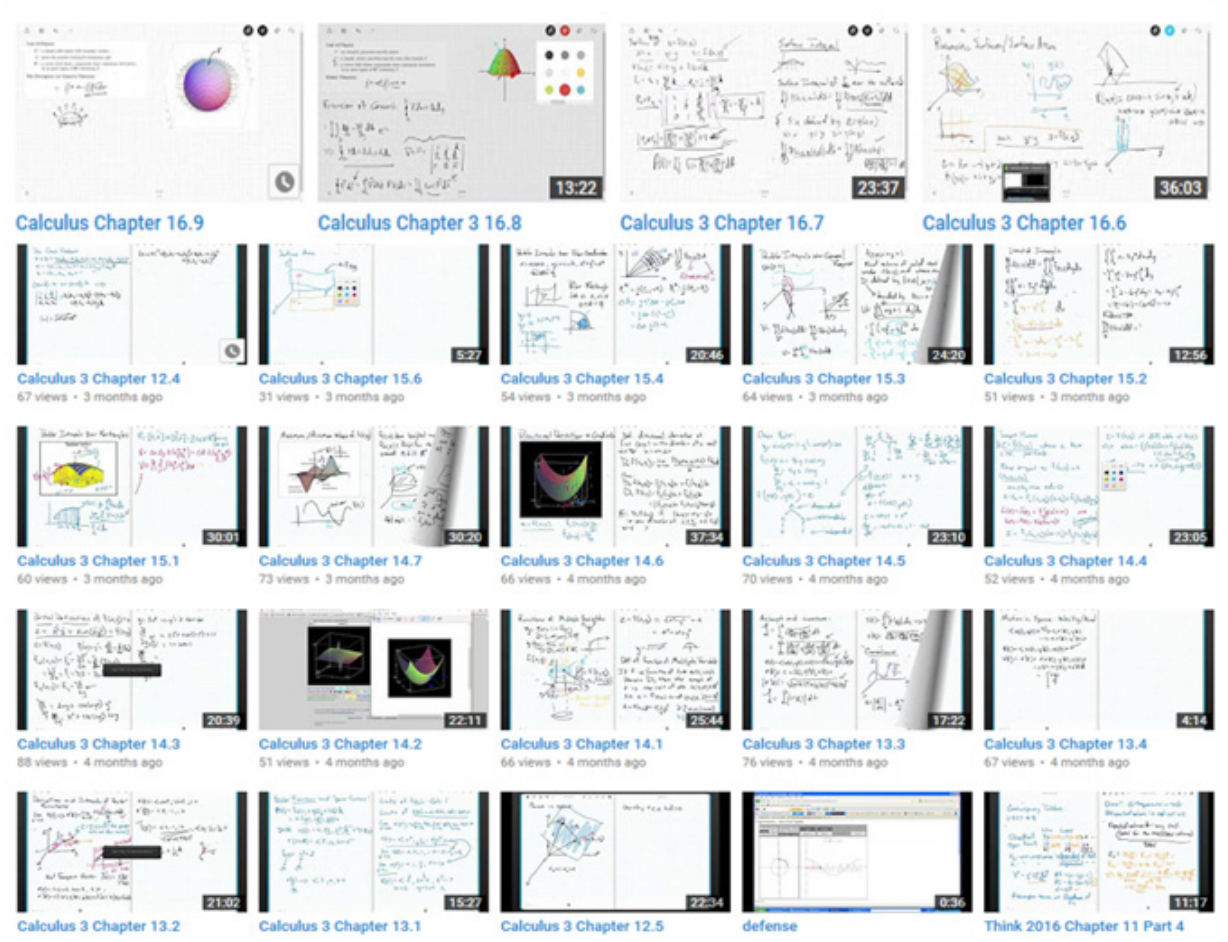

Figure 4. Sample instructional videos for a flipped Calculus class (Ripley, 2016) 
3. During the viewing of the video, students are required to take notes, for which they will be given credit upon their return to the classroom.

4. After viewing the videos, students are required to attempt the sample problems, for which they are given credit upon their return to the classroom. These problems are always taken from odd numbered problems, such that students can check their work in the back of the book after each attempt.

In-Class Procedures. Students are expected to be prepared when come to the class. During the class time, expectations for students are:

1. Students will turn in the assignment from the previous days "homework".

2. Students will come prepared with their notes and sample problems ready to show the instructor. The instructor puts a simple sample problem on the board for the students to attempt while he walks around the classroom giving credit to the students who have both the notes and sample problems from the previous day's video. Students are given 1 point for having taken complete notes (this is a subjective measure given at the instructor's prerogative) and 1 point for having attempted the sample problems.

3. Then, the instructor takes the first few minutes of class to ask if there are any ideas which need to be clarified, and takes a minute to discuss the sample problem which was put on the board. The instructor can also take this opportunity to reinforce any key points, theories, skills, etc. which she/he feels the students need to understand.
4. Afterwards, the assignment (for this case, Chapter 2.1) is put on the board, and also in Blackboard. Students may then begin work on the assignment.

5. Any student who was unable to watch the video can either take the time in class to watch the video or meet with the instructor to go over the material, with the understanding that the assignment will be "homework" as opposed to work that will be completed in the classroom, with the assistance of the instructor.

6. Whilst the students are working on their assignment, the instructor may walk around the class offering assistance to any student who may require it, as well as using the opportunity to do formative assessments to measure student understanding of the materials. Instructors can also use this time to meet with students about grades, grade assessments, or deal with any discipline issues.

After class time, students will have time continue working on the assignment for the chapter. On the next day, students turn in the assignment for the chapter, which is worth 10 points for a total of 12 points when combined with the 2 points for notes and practice problems. In theory, the instructor should be able to grade and give back the assignment within a day, such as to provide feedback as quickly as possible.

\subsection{Case-Success and Student Responses}

With the same criteria to determine the case-success in the literature review, this flipped Calculus class is successful based on the assessment report from the instructor. First, in the formative assessment during class time while the instructor observed and evaluated student work, students all 
performed as expected. They demonstrated the understanding of the content materials, and successfully solved the problems assigned in class. Secondly, the summative assessment for that particular class is the chapter assignment that students completed and turned in on the next day. They all met the required standards (The flipped classes continued through the semester and students all met the course requirements).

A feedback section was conducted with the students. They were satisfied with the flipped Calculus class by this instructor. However, when being asked whether participation of a flipped classroom motive their learning in general, five of the 25 students $(20 \%)$ answered "yes", two (8\%) answered "no", and $18(72 \%)$ answered "depends on the instructor." According to the instructor's observation, students definitely were highly motivated and engaged in the flipped learning. What might be reason that such a large portion of students in the class had a feedback of "depends on the instructor?" They may have had different flipped-experiences with other instructor(s). And, obviously the way current instructor flipped the class did fit his students' interests and produced expected learning outcomes.

\subsection{Case-Success and the Instructor's Tips}

The case procedures described above are in such operational-details that educators who are interested in flipping their classrooms could duplicate the experiences. In a follow up interview, the instructor also summarized some very valuable and applicable tips:

1. The benefit of a flipped classroom: (a) for the instructor is that it helps in building of rapport and a working relationship with students; and (b) for students is that they have unfettered access to the expert in the field whenever they need it, and they also learn to become independent learners

2. Start slow. An instructor may use summers and breaks to learn how to use the technologies, and all of their idiosyncrasies. In the first year of flipping, take perhaps $10 \%$ of the lessons and trouble shoot, debug, assess, and evaluate to see if flipping is a reasonable technique for his/her course/teaching style. Flipping isn't for everyone and every class!

3. If an instructor isn't comfortable with technology, collaborative learning, and letting go of some degree of control in the classroom, flipping won't work.

4. Flipping appears to work best in the hard sciences such as mathematics and the lab sciences, however, flipping is on a continuum and modifications can be used across all subject areas to incorporate flipping in varying degrees.

5. If the instructor feels that some of the students are not understanding content, even after viewing the videos and attempting the practice problems, "mini clinic" can be set up to remediate any issues with students, which speaks to the heart of flipping; it allows instructors time with students to insure their understanding.

6. Instructional design procedures should be naturally applied through the design of each component in a flipped class. For the instructor of this case, theory of choice is the ADDIE model.

These tips and case procedures from the instructor's first-hand experiences to certain extent do provide specific guidance for educators to start their flipped classes. 


\subsection{Case-Success and the Prediction Model}

This flipped learning case has successfully achieved the learning goals set for Chapter 2.1 from Stewart's Calculus: Early Transcendentals (7th Edition, 2015). It has also reflected the prediction model derived from the literature analysis. All five predictor factors (Overall Design, Design of Information, Design of Technology Use, Active Learning, and Motivation) were clearly addressed in the case procedures.

Considering the needs of flexible instruction format, capabilities and learning styles of learners, faculty qualification, available technology tools and support, the instructor ensured the "readiness" to flip the Calculus classroom. In the design of intentional contents, the presentations in video lectures, materials and assignments before class and in class are all carefully selected and developed for the flipped learning. Then, technology tools used to create the videos and online learning system to deliver the course content or perform learning activities were appropriately selected and integrated into the course design.

Furthermore, students were engaged in active learning from pre-learning, studentteacher collaboration, peer-peer collaboration and problem solving. Students were motivated by their curiosity to obtain new knowledge, the flexible ways to learn, available access to materials, assistance from the instructor, and points awarded for each piece of work. Overall, this case can be an example of the prediction model.

For the purpose to "examine" the prediction model, first the variables are identified from the case and coded. Next the logistic regression equation (1) is used to calculate $\log$ odds, which can then be converted into the probability of this flipped case to be successful. In this case, all five predictors variables are coded as " 1 " and the calculation procedures are as the following:

1. Calculating the log odds with equation (1):

$\log$ odds $=-1.628+0.898 * 1+0.869 * 1+$ $0.915 * 1+0.744 * 1+0.773 * 1=2.571$

2. Calculating odds:

odds $=\exp (2.571)=13.078$

(exp - exponential function)

3. Converting odds to probability:

$$
\begin{aligned}
\text { prob } & =13.078 /(1+13.078)=0.929 \\
& =92.9 \%
\end{aligned}
$$

According to the prediction model generated from the flipped case literature, the probability of the flipped Calculus class to be successful is $92 \%$. The model correctly predicted the success of the case.

\section{Discussions and Conclusions}

In summary, Overall Design, Design of Information, Design of Technology Use, Active Learning, and Motivation are the five predictor variables identified from the cases reported in the literature of flipped learning. A model to predict the success of a flipped case is generated with these five variables. The model is examined with a flipped Calculus class, and it successfully predicts the outcomes of the case.

\subsection{Conclusion One: Design Matters}

Based on the findings from the literature case analysis and the case of flipped Calculus class, a simple and clear conclusion is: to produce positive outcomes from flipped learning, design matters; the design needs to 
be conducted at two dimensions (content and technology) and in two layers (theoretical and practical).

As described in the ITD model (Liu \& Henderson, 2003), learning contents and use of technology tools are the two dimensions where to implement the tasks and activities of design defined by the ADDIE model (Branson, et al, 1975; Gagne, et al, 2005), such as goal setting, content analysis, instruction procedures, evaluation criteria, and technology integration. While implementing those tasks and activities, decisions are derived from applying relevant theories into specifying concrete tasks. For example, theories of active learning and selfregulated learning are especially the base to develop flipped learning activities, such as pre-learning or collaborative learning. All the procedures and tasks at each dimension and each layer are logically connected, formulating a framework for the design of flipped learning.

Since Liu and Henderson (2003) summarized the ITD model, it has been examined through a series of studies including experimental, quasi-experimental, and metaanalysis (Liu \& Johnson, 2002; Liu \& Jones, 2004; Lin \& Maddux, 2005, 2008a, 2008b, 2010). Findings consistently demonstrate the weight of "design" in the success of technology based learning. The current case of flipped Calculus class continually exhibits this consistence. However, very often design is still ignored, as shown in the variation in the response variable Case-Success (CS) from the case analysis results. In total 216 cases from the literature, 61 are absent in Overall Design (28\%), 115 are absent in Design of Information $(53 \%), 88$ are absent in Design of Technology Use (41\%), and totally 149 cases are successful $(69 \%)$. The absence of design does influence the success of a flipped learning case.

Volume 9, No. 2, December, 2016

\subsection{Conclusion Two: Instructor Matters}

A second conclusion from this study is: to create a well-designed course package and to motivate students' flipped learning, the instructor matters; the instructor needs to be hard-working, skilled, sensitive to student needs, and willing to explore new or innovative applications in education.

In the cases selected for review and analysis, most describe the activities, procedures, or learning environment created by the instructor, which in deed demonstrates the quality of the instructor's work, and whether he/she is skillful in instructional design. For example, in the cases absent in content design, instructional contents are delivered, but the contents are not specifically designed for a flipped classroom. In such case, the instructor is not ready to flip his/her class yet. In some other cases, instructional design principles and components are clearly laid out through the entire learning procedures, which demonstrates the instructor's knowledge and skills in design, in technology, and in the subject area.

The instructor in the flipped Calculus course is a typical example. He is a dedicated teacher with strong background knowledge and skill, especially in instructional design and technology. His dedicated work helps students meet their full potential of learning. Another example is a successful flipped Sociology course at a community college in a western state (Lee \& Liu, 2016). The instructor uses self-created video lectures, emphasizes the approach of active learning in her design, and develops good rapports with her students through collaborative activities before, in and after classes.

Moran and Liu (2011) analyzed the standards and features of "Teacher of the Year" from over 30 states in the United States, 
and summarized a set of criteria contributing to high quality teaching. Consistent with the findings in the case analysis, "appropriate design of instruction" is one of the criteria. Again, design matters, on condition that the instructor is ready to flip.

\subsection{Non-significant Variables and the Model}

In developing the prediction model, two original explanatory variables (Special Guidance, and Self-Regulated Learning) are not significant. They are eliminated from the model. The fact that these two variables are not statistically significant does not mean they are not important to flipped learning. Actually, these two variables are also under the scope of design, relating to the design of teaching method, learning activities, and evaluation strategies.

The model with all seven variables including these two was still significant $\left(\mathrm{X}^{2}=\right.$ $44.485, p<0.001)$ and accounted for about $21 \%$ of the variation in the response variable $\left(\mathrm{R}^{2}=0.212\right)$. However, these two variables just did not contribute to the model, and the variation of the response variable, so they were not included in the model. One reason that they are not significant may be because that they are applied in both successful and unsuccessful cases, so the variation of their contribution to the response variable is reduced. Nonetheless, from the perspective of practice, definitely they deserve serious attention from the instructor or course designer.

\subsection{Limitations and Further Studies}

The purpose of this study is to explore factors that influence the success of a flipped case as described in the literature. The authors of this article focus on identifying the variables, developing and examining the prediction model. One limitation of this article is that the descriptions of theories referred in this article (such as ADDIE model, ITD model, active learning, and self-regulatedlearning) are not expanded in depth, as they are the common theories and models used in the field of instructional design and technology. The authors efforts are made more on the exploration of best practice in flipped learning.

This prediction model, although it is based on flipped learning literature, can still be applied in a general education setting. It is the authors' hope that findings from this article could provide useful reference to other educators and researchers, and generate more research ideas. Further studies could be conducted (a) to examine the validity and reliability of this model with larger size of data, (b) to examine the effectiveness of using this model on student learning with experimental design, or (c) to explore more relevant factors and revise this model. We welcome any comments and suggestions. 


\section{References}

Davies, R. S., Dean, D. L., \& Ball, N. (2013). Flipping the classroom and instructional technology integration in a college-level information systems spreadsheet course. Educational Technology Research and Development, 61(4), 563-580.

Baepler, P., Velegol, S. B., Zappe, S. E., \& Mahoney, E. (2015). The Evolution of a Flipped Classroom: EvidenceBased Recommendations. Advances in Engineering Education, 4(3), 1-37.

Baepler, P., Walker, J. D., \& Driessen, M. (2014). It's not about seat time: Blending, flipping and efficiency in active learning classrooms. Computers \& Education, 78, 227-236.

Branson, R. K., Rayner, G. T., Cox, J. L., Furman, J. P., \& King, F. J. (1975). Interservice procedures for instructional systems development. Executive summary and model. FLORIDA STATE UNIV TALLAHASSEE CENTER FOR EDUCATIONAL TECHNOLOGY.

Chai, C. S., Wong, L. H., \& King R. B. (2016). Surveying and modeling students' motivation and learning strategies for mobile-assisted seamless Chinese Language Learning. Educational Technology and Society, 19(3), 170-180.

Chen, C. M. (2009). Personalized E-learning system with self-regulated learning assisted mechanisms for promoting learning performance. Expert System with Applications, 36, 8816-8829.

Chen, Y., Wang, Y, Kinshuk, C., \& Chen, N. (2014). Is FLIP enough? Or should we use the FLIPPED model instead? Computer Education, 79(1), 16-27.

Enfield, J. (2013). Looking at the Impact of the Flipped Classroom Model of Instruction on Undergraduate Multimedia Students at CSUN. TechTrends: Linking Research and Practice to Improve Learning, 57(6), 14-27.

Engin, M. (2014). Extending the flipped classroom model: Developing second language writing skills through studentcreated digital videos. Journal of the Scholarship of Teaching and Learning, 14(5), 12-26.

Flipped Learning Network (2014). The four pillars of F-L-I-P. Retrieved from

http://www.flippedlearning. org/definition

Fulton, K. P. (2014). Time for Learning: Top 10 Reasons Why Flipping the Classroom Can Change Education. Corwin Press.

Gagne, R. M., Wager, Q. W., Golas, K. C., \& Keller, J. M. (2005). Principles of Instructional Design ( $5^{\text {th }}$ Ed.). Belmont, CA: Wadsworth/Thomson Learning.

Gojak, L. (2012). To Flip or Not to Flip: That is Not the Question! National Council of Teachers of Mathematics. Retrieved February $6^{\text {th }}$ from http://www.nctm.org/ about/content.aspx? id $=34585$

Goodwin, B., \& Miller, K. (2013). Evidence on flipped classrooms is still coming in. Educational Leadership, March, 78-80.

Google Trends. (2016). Flipped learning. Retrieved from https://www.google.com/ trends/explore?q=flipped\%20learning

Hamdan, N., McKnight, P., McKnight, K., \& Arfstrom, K. M. (2013). A review of flipped learning. Flipped Learning Network.

Herreid, C. F., \& Schiller, N. A. (2013). Case studies and the flipped classroom. Journal of College Science Teaching, 42(5), 6266.

Holmes, M. R., Tracy, E. M., Painter, L. L., Oestreich, T., \& Park, H. (2015). Moving from flipcharts to the flipped classroom: using technology driven teaching methods to promote active learning in foundation and advanced masters social work courses. Journal of Clinic Social Work, 43, 215224. 
Huba, M. E., \& Freed, J. E. (2000). LearnerCentered Assessment on College Campuses: Shifting the Focus from Teaching to Learning.

King, A. (1993). From Sage on the Stage to Guide on the Side. College Teaching. 41 (1), 30.

Lee, A. M., \& Liu, L. (2016). Examining flipped learning in sociology courses: A quasi-experimental design. International Journal of Technology in Teaching and Learning, 11(2), 47-64.

Leung, J. Y. C., Kumta, S. M., Jin, Y., \& Yung, A, L. K. (2014). Short review of the flipped classroom approach. Medical Education, 48, 1104-1132.

Liu, L., \& Henderson, N. J. (2003). An information technology integration system and its life cycle: What is missing? Computers in the Schools, 20 (1/2), p. 93 106.

Liu, L., \& Johnson, D. L. (2002). Assessing student learning in instructional technology courses within the dimensions of learning model: Static versus dynamic assessment. Computers in the Schools, 18(2/3), 79-95.

Liu, L., \& Jones, P. (2004). Impact of online communication design on student motivation and performance. Journal of Research on Education, 14(1), 40-56.

Liu, L., \& Maddux, C. (2005). Influences of course design on student evaluations: An initial logistic prediction model. Journal of Excellence in College Teaching,16(1),125-148.

Liu, L., \& Maddux, C. (2008a). Web 2.0 articles: Content analysis and a statistical model to predict recognition of the need for new instructional design strategies. Computers in the Schools, 25(3/4), 314328.

Liu, L., \& Maddux, C. (2008b). Examining the Predictive Validity of an Instrument: Technology Attitudes and Learning.
Computers in the Schools, 25(1/2), 145158.

Liu, L., \& Maddux, C. (2010). Using dynamic design in the integration of type II applications: Effectiveness, strategies and methods. International Journal of Technology in Teaching and Learning, 6(1), 71-88.

Liu, L., Maddux, C., \& Johnson, D. L. (2008). Assessment of integration of technology in education: Countering the "no significant differences" argument. Computers in the Schools, 25(1-2), 1-9.

Moran, J., \&Liu, L. (2011).Criteria contributing to high quality teaching. In V. Wang, (ed.), Encyclopedia of E-Leadership, counseling and Training (pp. 601-615). Hershey, PA: IGI Global.

McLaughlin, J. E., Gharkholonarehe, N., \& Esserman, D. A., (2014). The flipped classroom: A course redesign to foster learning and engagement in a health professions school. Academic Medicine, 89(2), 236-243.

Michael, J. (2006). Where's the Evidence that Active Learning Works? Advances Physiology Education, 30, 159-167.

Musallam, R. (2012). Blog. Cycles of Learning. Retrieved October 15 , 2012 from

http://www.cyclesoflearning.com

Ng, W. (2014). Flipped learning: The Science classroom exploring merits, issues and pedagogy.

Teaching Science, 69(3), 16-26.

Persky, A. M., \& Dupuis, R. E. (2014). An eight-year retrospective study in "Flipped" pharmacokinetics courses. American Journal of Pharmaceutical Education, 78(10), 1-7.

Prince, M. (2004). Does Active Learning Work? A Review of the Research. Journal of Engineering Education, 93, 223-231.

Project Tomorrow. (2015). Speak up 2014 national research project findings: Flipped 
learning continues on trend for third year. Speak Up. Retrieved from http:// www.tomorrow.org/ speakup/downloads/ SpeakUpFLN_2014Survey\%20Results. pdf.

Ripley, D. (2016). Instructional videos for my flipped classes. Retrieved from

ht tps://www.youtube.com/user/ ThinkSummer2012/videos

Roach, T. (2014). Student perceptions toward flipped learning: New methods to increase interaction and active learning in economics. International Review of Economics Education, 17, 74-84.

Roehl, A., Reddy, S. L., \& Shannon, G. J. (2013). The flipped classroom: An opportunity to engage millennial students through active learning strategies. Journal of Family \& Consumer Sciences, 105(2), 44-49.

Sams, A., \& Bergmann, J. (2013). Flip your students' learning. Educational Leadership, March, 2013. 16-21.

Stewart, J. (2015). Calculus: Early Transcendentals (7th Ed.) Cengage Learning. http://www. cengage.com/

Strayer, J. F. (2012). How learning in an inverted classroom influences cooperation, innovation and task orientation. Learn Environ Res 15, 171-193.

Velegol, S. B., Zappe, S. E., \& Mahoney, E. $(2015)$. The Evolution of a Flipped Classroom: Evidence-Based Recommendations. Advances in Engineering Education, 4(3), 1-37.

Zimmerman, B. J., \& Schunk, D. H. (2001). Self-regulated learning and academic achievement: theoretical perspectives. Mahwah, New Jersey: Lawrence Erlbaum.

\section{Contact the Author}

\section{Leping Liu}

Professor,

Information Technology in Education,

College of Education

University of Nevada, Reno, USA

Email: liu@unr.edu

\section{Darren Ripley}

PhD, Head of Math Department, Davidson Academy of Nevada

University of Nevada, Reno, USA

Email: dripley@davidsonacademy.unr.edu

\section{Angela Lee}

$\mathrm{PhD}$, Manager of online program,

National Judicial College

University of Nevada, Reno, USA

Email: Alee3@unr.edu 